\title{
Magnesium ions mitigate biofilm formation of Bacillus species via downregulation of matrix genes expression
}

\author{
Hilla Oknin ${ }^{1,2}$, Doron Steinberg ${ }^{2}$ and Moshe Shemesh ${ }^{1 *}$ \\ ${ }^{1}$ Department of Food Quality and Safety, Institute for Postharvest Technology and Food Sciences, Agricultural Research \\ Organization, The Volcani Center, Bet-Dagan, Israel, ${ }^{2}$ Biofilm Research Laboratory, Faculty of Dental Medicine, Institute of \\ Dental Sciences, Hebrew University-Hadassah, Jerusalem, Israel
}

\section{OPEN ACCESS}

Edited by:

Beiyan Nan

Taxas A\&M University, USA

Reviewed by:

Anushree Malik,

Indian Institute of Technology Delhi,

India

Robert Lawrence Brown,

Agricultural Research Service, USA

${ }^{*}$ Correspondence:

Moshe Shemesh,

Department of Food Quality and

Safety, Institute for Postharvest

Technology and Food Sciences, Agricultural Research Organization, The Volcani Center,

50250 Bet-Dagan, Israel moshesh@agri.gov.il

Specialty section:

This article was submitted to

Food Microbiology,

a section of the journal

Frontiers in Microbiology

Received: 21 May 2015

Accepted: 19 August 2015 Published: 08 September 2015

Citation:

Oknin $H$, Steinberg $D$ and Shemesh $M$ (2015) Magnesium ions mitigate biofilm formation of Bacillus species via downregulation of matrix genes expression. Front. Microbiol. 6:907. doi: 10.3389/fmicb.2015.00907
The objective of this study was to investigate the effect of $\mathrm{Mg}^{2+}$ ions on biofilm formation by Bacillus species, which are considered as problematic microorganisms in the food industry. We found that magnesium ions are capable to inhibit significantly biofilm formation of Bacillus species at $50 \mathrm{mM}$ concentration and higher. We further report that $\mathrm{Mg}^{2+}$ ions don't inhibit bacterial growth at elevated concentrations; hence, the mode of action of $\mathrm{Mg}^{2+}$ ions is apparently specific to inhibition of biofilm formation. Biofilm formation depends on the synthesis of extracellular matrix, whose production in Bacillus subtilis is specified by two major operons: the epsA-O and tapA operons. We analyzed the effect of $\mathrm{Mg}^{2+}$ ions on matrix gene expression using transcriptional fusions of the promoters for eps and tap $A$ to the gene encoding $\beta$ galactosidase. The expression of the two matrix operons was reduced drastically in response to $\mathrm{Mg}^{2+}$ ions suggesting about their inhibitory effect on expression of the matrix genes in $B$. subtilis. Since the matrix gene expression is tightly controlled by SpoOA dependent pathway, we conclude that $\mathrm{Mg}^{2+}$ ions could affect the signal transduction for biofilm formation through this pathway.

Keywords: biofilm formation, magnesium ions, food industry, Bacillus species, microbial development

\section{Introduction}

The vast majority of bacteria often grow as elaborate multicellular communities, referred to as biofilms (Hall-Stoodley et al., 2004; Kolter and Greenberg, 2006). Biofilm formation represents one of the most successful strategies for survival in natural environments, which protect bacteria and facilitates growth under unfavorable conditions, such as turbulent flow or limited access to nutrients (Stewart and Costerton, 2001; Hall-Stoodley et al., 2004). Biofilm formation is a multistage process in which cells adhere to a surface through production of an extracellular matrix that is typically composed of polysaccharides, proteins, and nucleic acids (Flemming and Wingender, 2010). These exopolymeric substances often surround and protect the bacteria (Shemesh et al., 2010). Thus, biofilm bacteria are more resistant than planktonic cells to various antimicrobials (Costerton, 1999; Mah and O'Toole, 2001).

Biofilms are problematic in a broad range of areas, and specifically in the food, environmental, and biomedical fields (Simoes et al., 2010). Within food industry, biofilm formation in dairy 
processing plants is a most significant problem. The major source of the contamination of dairy products is often associated with biofilms (Flint et al., 1997), particularly biofilms formed by members of the Bacillus genus (Sharma and Anand, 2002; Simoes et al., 2010). As Bacillus species are ubiquitously present in nature, they easily spread through food production systems, and contamination with these species is almost inevitable. The biofilm formed by thermo-resistant Bacillus species in a milk line can rapidly grow to such an extent that the passing milk is contaminated with cells released from the biofilm (Wirtanen et al., 1996). Thus, biofilms formed by Bacillus species is the major type of hygiene problems in dairy industry.

Clearly, preventing biofilm formation would be a much more desirable option than affecting it in the maturation stage, therefore a range of antimicrobial strategies have been proposed to control biofilms. However, conventional cleaning and disinfection regimens or present antimicrobial strategies may contribute to inefficient biofilm control and to the dissemination of resistance (Simoes et al., 2010). Hence, techniques that are able to prevent or control the formation of unwanted biofilms may have adverse side effects. Therefore, it necessitates looking for other methods to prevent and eradicate bacterial biofilms more successfully.

Environmental factors such as electrolyte concentrations and medium composition may have important impacts on biofilm formation (Song and Leff, 2006; Shemesh et al., 2007). Divalent cations, such as $\mathrm{Mg}^{2+}$ and $\mathrm{Ca}^{2+}$, can influence biofilm formation directly through their effect on electro-static interactions and indirectly via physiology-dependent attachment processes by acting as important cellular cations and enzyme cofactors (Fletcher, 1988; Malik and Kakii, 2003; Song and Leff, 2006). In spite of the potentially important role, the effect of $\mathrm{Mg}^{2+}$ ions on bacterial adhesion and biofilm formation has barely been studied. $\mathrm{Mg}^{2+}$ has been shown to influence adherence to surfaces in Pseudomonas spp. (Simoni et al., 2000). Moreover, in Aeromonas hydrophilia, mutations in $\mathrm{Mg}^{2+}$ transport systems result in reduction of swarming and biofilm formation (Merino et al., 2001). Accordingly to Dunne and Burd (1992), $16 \mathrm{mM}$ of $\mathrm{Mg}^{2+}$ significantly enhanced in vitro adhesion of Staphylococcus epidermidis to plastic (Dunne and Burd, 1992). In addition, it was reported that increase in $\mathrm{Mg}^{2+}$ concentrations affected positively on biofilm formation by $P$. fluorescens (Song and Leff, 2006). Also, it was hypothesized that low $\mathrm{Ca}^{2+}$ or $\mathrm{Mg}^{2+}$ concentrations have the potential to inhibit biofilm formation by some A. flavithermus and Geobacillus spp. strains during the processing of milk formulations (Somerton et al., 2013). Another recent study has showed that biofilm formation decreased with increasing concentration of $\mathrm{Mg}^{2+}$ in Enterobacter cloacae (Zhou et al., 2014). Although recent studies have shown that magnesium might have diverse effects on biofilms, the effect of $\mathrm{Mg}^{2+}$ ions on biofilm formation by sporulation Bacillus species remains largely unknown. Therefore, the purpose of this study was to investigate the effect of $\mathrm{Mg}^{2+}$ ions on biofilm formation by Bacillus species, which are potential importance of biofilm formation in food industrial settings.

\section{Materials and Methods}

\section{Strains and Growth Media}

The Bacillus subtilis wild strain NCIB3610 (Branda et al., 2001) and Bacillus cereus ATCC 10987 stain, obtained from Michel Gohar's lab collection (INRA, France), were used in this study. For fluorescent microscopy, we used a strain (YC161 with $P_{\text {spank }}{ }^{-}$ $g f p$ ) that produced GFP constitutively (Chai et al., 2011) which was obtained from the laboratory collection of Yunrong Chai (Northeastern University, USA). For routine growth, all strains were propagated in Lysogeny broth (LB; $10 \mathrm{~g}$ of tryptone, $5 \mathrm{~g}$ of yeast extract and $5 \mathrm{~g}$ of $\mathrm{NaCl}$ per liter) or on solid LB medium supplemented with $1.5 \%$ agar. For biofilm generation, bacteria were grown to stationary phase in $\mathrm{LB}$ medium at $37^{\circ} \mathrm{C}$ in shaking culture to around $1 \times 10^{8} \mathrm{CFU}$ per ml. Biofilms were generated at $30^{\circ} \mathrm{C}$ in the biofilm promoting medium LBGM ( $\mathrm{LB}+1 \%$ $(\mathrm{v} / \mathrm{v})$ glycerol $+0.1 \mathrm{mM} \mathrm{MnSO}_{4}$ ) (Shemesh and Chai, 2013). To test the effect of magnesium, sodium or calcium ions on biofilm formation, different concentrations of either $\mathrm{MgCl}_{2}$ (Merck $\mathrm{KGaA}$ ), $\mathrm{NaCl}$ (BIO LAB LTD), or $\mathrm{CaCl}_{2}$ (Merck KGaA) were added directly into the LBGM medium. For colony type biofilm formation, $3 \mu$ l of the cells (around $3 \times 10^{5} \mathrm{CFU}$ ) was spotted onto LBGM medium solidified with $1.5 \%$ agar as described previously (Shemesh and Chai, 2013). Plates were incubated at $30^{\circ} \mathrm{C}$ for $72 \mathrm{~h}$ prior to analysis. For pellicle formation, $5 \mu \mathrm{l}$ of the cells (around $5 \times 10^{5} \mathrm{CFU}$ ) was mixed within $4 \mathrm{ml}$ of LBGM broth in 12-well plates (Costar). Plates were incubated at $30^{\circ} \mathrm{C}$ for $24 \mathrm{~h}$. Images were taken using a Zeiss Stemi 2000-C microscope with an axiocam ERc 5s camera.

For experiments performed with $B$. cereus, bacteria were grown to stationary phase in $\mathrm{LB}$ medium at $37^{\circ} \mathrm{C}$ in shaking culture to around $5 \times 10^{7} \mathrm{CFU}$ per $\mathrm{ml}$. For pellicle formation, $5 \mu \mathrm{l}$ of the cells (around $2.5 \times 10^{5} \mathrm{CFU}$ ) was mixed within $4 \mathrm{ml}$ of LBGM broth in glass tubes in the presence or absence of different concentration of $\mathrm{MgCl}_{2}$. The glass tubes were incubated at $30^{\circ} \mathrm{C}$ for $24 \mathrm{~h}$.

\section{Assay of $\beta$-galactosidase Activity}

To analyze the effect of magnesium ions on matrix gene expression we used transcriptional fusions of the promoters for eps and tapA to the gene encoding $\beta$ galactosidase (Chai et al., 2008). Samples of generated pellicles as described above were collected and resuspended in phosphate-buffered saline (PBS) buffer. Typical long bundled chains of cells in the biofilm colony were disrupted using mild sonication as described previously (Branda et al., 2006). Optical density of the cell samples was normalized using $\mathrm{OD}_{600}$. One milliliter of cell suspensions was collected and assayed for $\beta$-Galactosidase activity as described previously (Chai et al., 2008).

\section{Growth Curve Analysis}

Initially, the cells were grown in shaking cultures over night at $23^{\circ} \mathrm{C} / 150 \mathrm{rpm}$ in $\mathrm{LB}$ to around $2 \times 10^{9} \mathrm{CFU}$ per ml. On the next morning, the cultures were diluted 1:100 (to around $2 \times 10^{7} \mathrm{CFU}$ ) into LBGM with or without addition of different concentration of $\mathrm{MgCl}_{2}$ and incubated at $37^{\circ} \mathrm{C}$ at $150 \mathrm{rpm}$. The absorbance of the cultures at $600 \mathrm{~nm}$ was measured periodically for each culture 
for $9 \mathrm{~h}$. Each condition had three replicates, and the growth curve experiments were repeated twice. Representative results are shown.

\section{Fluorescent Microscopy Analysis}

For fluorescent microscopy, we used a strain YC161 that produced GFP constitutively. The strain was first grown in shaking culture for $5 \mathrm{~h} 37^{\circ} \mathrm{C} / 150 \mathrm{rpm}$ in LB to around $1 \times$ $10^{8} \mathrm{CFU}$ per ml. Next, $5 \mu \mathrm{l}$ (around $5 \times 10^{5} \mathrm{CFU}$ ) of suspension from the generated culture was introduced into $4 \mathrm{ml}$ of LBGM medium and incubated at $30^{\circ} \mathrm{C}$ for $24 \mathrm{~h}$ statically. Afterwards, one milliliter of suspension from each sample was collected, mildly sonicated (10 s/20\% Amp/5) and centrifuged at $5000 \mathrm{rpm}$ for $2 \mathrm{~min}$. Next, the supernatant was removed and the pellet was resuspended by pipetation. For microscopic observation, $3 \mu \mathrm{l}$ from the samples were transferred onto a glass slide and visualized in a transmitted light microscope using Nomarski differential interference contrast (DIC), at x40 magnification. A confocal laser scanning microscope was used to visualize GFP expression of strain YC161 using an Olympus IX81 confocal laser scanning microscope (CLSM) (Japan) equipped with $488 \mathrm{~nm}$ argon-ion and $543 \mathrm{~nm}$ helium neon lasers. For experiments performed with $B$. cereus, the cells were stained with CYTO 9 from the FilmTracer ${ }^{\mathrm{TM}}$ LIVE/DEAD Biofilm Viability Kit (Molecular Probes, OR) following instructions of the manufacturer. Fluorescence emission of the stained samples was determined using an Olympus IX81 confocal laser scanning microscope (Japan) equipped with $488 \mathrm{~nm}$ argon-ion and $543 \mathrm{~nm}$ helium neon lasers.

\section{Statistical Analysis}

Statistical analysis was performed using $T$-test to compare the control and tested samples. Statistical significant was determined at $P<0.05$.

\section{Results}

The starting point of this investigation was the observation that at the elevated concentrations $\mathrm{Mg}^{2+}$ ions could inhibit biofilm formation by B. subtilis. As seen in Figure 1, $\mathrm{Mg}^{2+}$ ions inhibited notably pellicle formation by $B$. subtilis in a concentration dependent manner. The inhibitory effect of $\mathrm{Mg}^{2+}$ ions was not restricted to $\mathrm{MgCl}_{2}$ compound since we found that other magnesium salts, such as $\mathrm{MgSO}_{4}$ have also inhibited the pellicle formation (data not shown). This indicates that the inhibitory effect of magnesium salts is attributed to $\mathrm{Mg}^{2+}$ ions. Moreover, colony type biofilm formation was also inhibited significantly in the presence of high concentrations of $\mathrm{Mg}^{2+}$ ions (Figure 1).

To confirm that the significant inhibition in biofilm formation by $\mathrm{Mg}^{2+}$ ions is not a result of toxicity to bacterial cells, we tested the effect of different concentrations of $\mathrm{Mg}^{2+}$ ions on bacterial growth. As shown in Supplementary Figure 1, the growth curve analysis suggests about very little effect of the $\mathrm{Mg}^{2+}$ ions on bacterial growth at the tested concentrations; hence, the mode of action of $\mathrm{Mg}^{2+}$ ions is apparently specific to inhibition of biofilm formation.

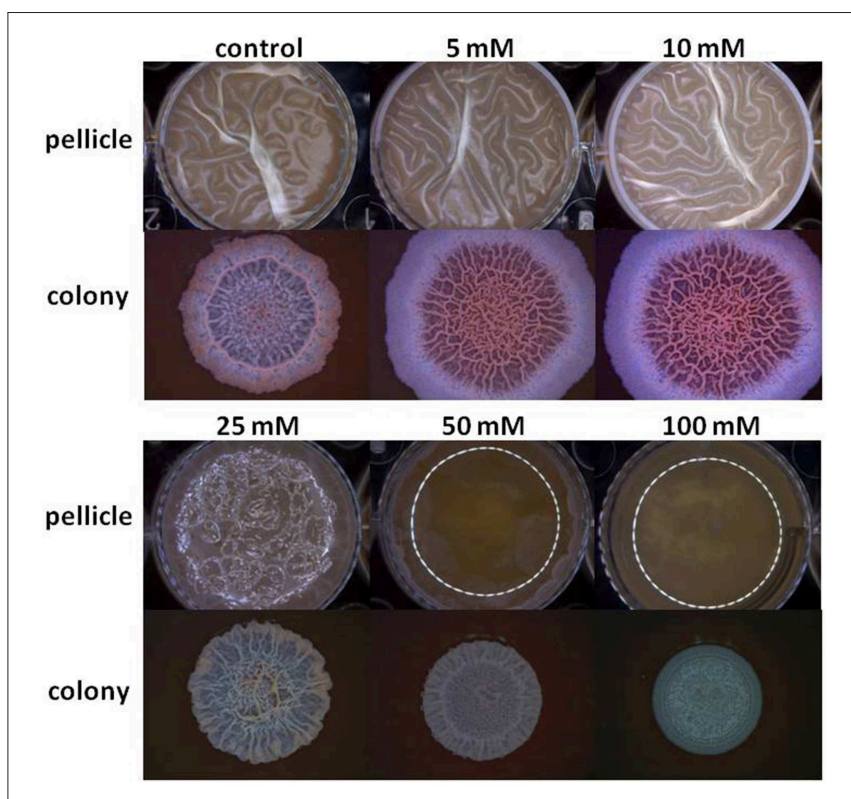

FIGURE 1 | $\mathbf{M g}^{2+}$ ions block biofilm formation of $\boldsymbol{B}$. subtilis. The effect of addition of different concentrations of $\mathrm{MgCl}_{2}$ to $\mathrm{LBGM}$ medium on pellicle and colony biofilm formation by B. subtilis NCIB3610.

Biofilm formation depends on the synthesis of extracellular matrix, whose production in $B$. subtilis is specified by two major operons: the epsA-O and tapA operons (Kearns et al., 2005; Branda et al., 2006; Chu et al., 2006). The epsA-O operon is responsible for the production of the exopolysaccharides whereas the tapA operon is responsible for the production of amyloid-like fibers (Chai et al., 2008; Romero et al., 2010). We hypothesized that the inhibitory effect of $\mathrm{Mg}^{2+}$ ions on biofilm formation could be due to down-regulation of the genes involved in matrix synthesis. To test this hypothesis, we analyzed the effect of $\mathrm{Mg}^{2+}$ ions on matrix gene expression using transcriptional fusions of the promoters for epsA-O and tapA to the gene encoding $\beta$ galactosidase. The expression of the matrix operons was notably reduced in response to the addition of $\mathrm{Mg}^{2+}$ ions (Figure 2A). The reduction in eps expression was relatively small (around four-fold) but significant, while tapA expression was decreased almost 14.5-fold at elevated concentrations of $\mathrm{Mg}^{2+}$ ions (Figure 2A). This result suggests that addition of $\mathrm{Mg}^{2+}$ ions down regulates expression of the extracellular matrix genes in B. subtilis.

Next, we visualized microscopically the effect of magnesium ions by testing bundling phenotype of fluorescently tagged B. subtilis cells (YC161 with $P_{\text {spank }}-g f p$ ), which produce GFP constitutively (Chai et al., 2011). As seen in Figure 3, there is significant reduction in bundling ability of $B$. subtilis cells in the presence of $25 \mathrm{mM} \mathrm{MgCl} 2$ and higher. This result further confirms the potential of $\mathrm{Mg}^{2+}$ ions to inhibit biofilm formation by B. subtilis.

Subsequently, we wondered whether other common salts may also affect the biofilm formation at the same concentration as it does $\mathrm{MgCl}_{2}$. Therefore, we tested the effect of $\mathrm{NaCl}$ and $\mathrm{CaCl}_{2}$ on biofilm formation by $B$. subtilis. Notably, none of 

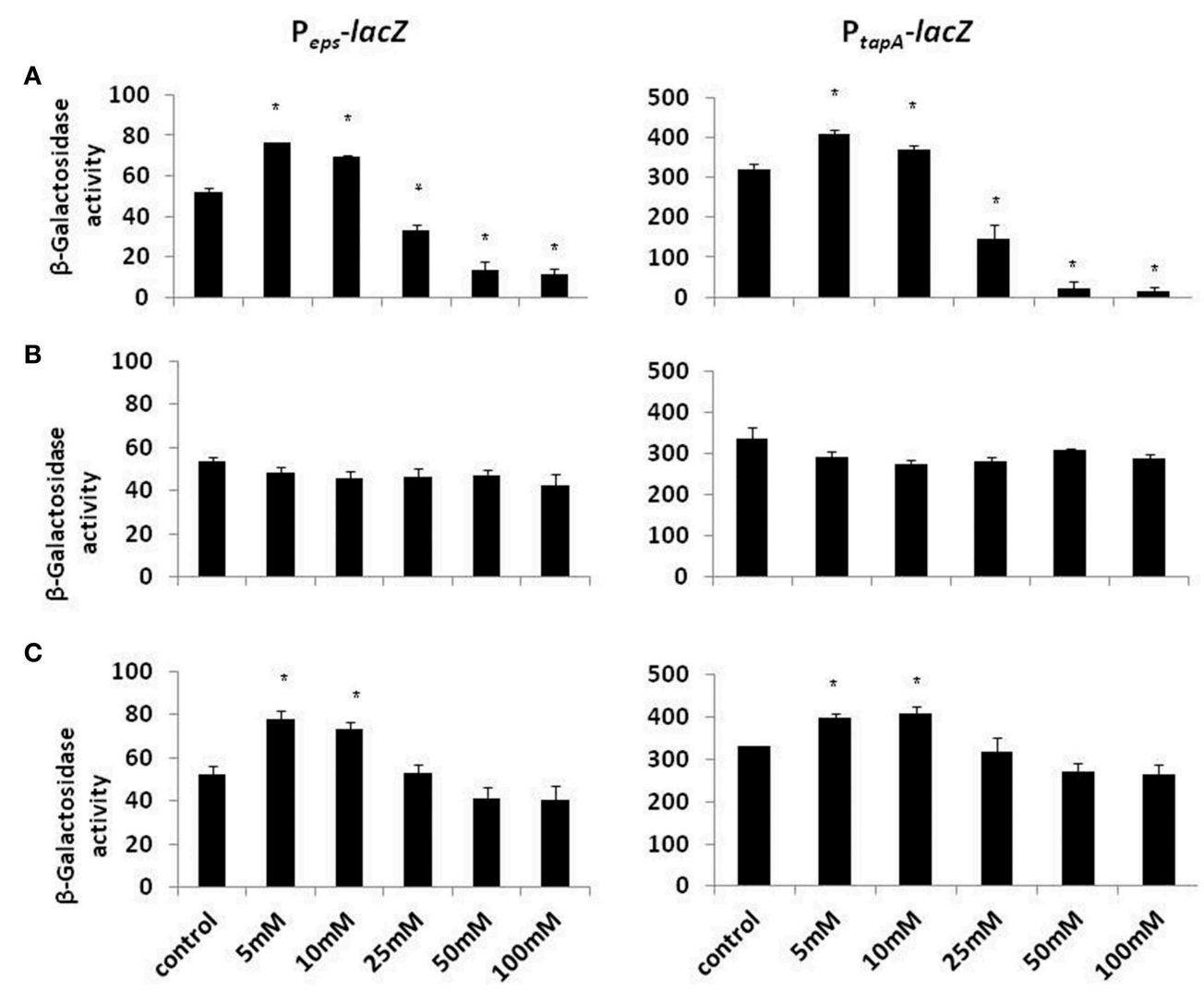

FIGURE 2 | The effect of $\mathrm{Mg}^{2+}, \mathrm{Ca}^{2+}$, and $\mathrm{Na}^{+}$ions on transcription of the operons responsible for the matrix production. Transcription of the operons responsible for the matrix production is differentially regulated in response to $\mathbf{( A )} \mathbf{M g}^{2+}$, (B) $\mathrm{Na}^{+}$, and $(\mathbf{C}) \mathrm{Ca}^{2+}$ ions. The left panel shows results from RL4548 cells that bear the $P_{e p s}$-lacZ transcriptional fusion and the right panel demonstrates results from $R L 4582$ cells that bear the $P_{\text {tapA-lacZ }}$ transcriptional fusion; . ${ }^{*}$-value $<0.05$ compared to control.

those compounds could inhibit the biofilm formation in the same manner as $\mathrm{MgCl}_{2}$. Although, there was not a significant difference in pellicle formation or bundling ability of B. subtilis cells in the presence of $\mathrm{NaCl}$ at tested concentrations (Figure 4), nonetheless, $\mathrm{NaCl}$ could slightly affect the expression of eps operon at $100 \mathrm{mM}$ concentration (Figure 2B). Interestingly, we detected a very slight inhibition in the pellicle formation in the presence of $50 \mathrm{mM}$ or higher concentrations of $\mathrm{CaCl}_{2}$ (Figure 5), while expression of the eps and tapA operons was found to be somewhat downregulated (Figure 2C). It should be noted that neither $\mathrm{NaCl}$ nor $\mathrm{CaCl}_{2}$ affected notably bacterial growth (Supplementary Figures 2 and 3).

\section{Discussion}

It becomes increasingly clear that most of the bacteria in their natural state exist as surface associated matrix enclosed biofilms. Bacteria are much protected from environmental insults as well as various antimicrobial treatments in the biofilm mode of growth. Our results show that $\mathrm{Mg}^{2+}$ inhibits biofilm formation by $B$. subtilis at $25 \mathrm{mM}$ and higher concentration, although at low concentrations ( 5 and $10 \mathrm{mM}$ ) $\mathrm{Mg}^{2+}$ enhanced biofilm formation of B. subtilis. Apparently, the inhibitory effect of ions is conserved in other Bacillus species too. Using CLSM method, we observed a notable inhibition in biofilm formation by $B$. cereus (Supplementary Figure 5), while bacterial growth was not affected in the presence of $\mathrm{Mg}^{2+}$ ions (Supplementary Figure 4). Interestingly, the results of our study are in consistence with some of the previous findings regarding the effect of magnesium ions on bacterial adhesion and biofilm formation by different species. Previous studies have shown that $\mathrm{Mg}^{2+}$ has varying effects on bacterial adhesion (Marcus et al., 1989; Dunne and Burd, 1992; Tamura et al., 1994), which could be explained due to the difference in bacterial species and $\mathrm{Mg}^{2+}$ concentrations used in the various studies. For instance, Tamura et al. (1994) showed that $2 \mathrm{mM}$ magnesium had no significant effect on adherence of Streptococci, while higher concentrations enhanced adherence to a small degree (Tamura et al., 1994). Another study showed that at $16 \mathrm{mM}$ magnesium significantly enhanced the in vitro adhesion of S. epidermidis to plastic surface (Dunne and Burd, 1992). Additional study has showed that $\mathrm{Mg}^{2+}$ enhanced adherence of mucoid in one $P$. aeruginosa strain tested and showed no effect on the other (Marcus et al., 1989). It was further found that increase in $\mathrm{Mg}^{2+}$ concentrations positively influenced bacterial attachment but the effect changed over time during biofilm formation (Song and Leff, 2006). 


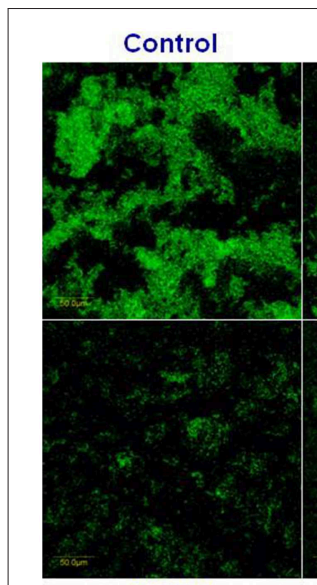

$25 \mathrm{mM}$

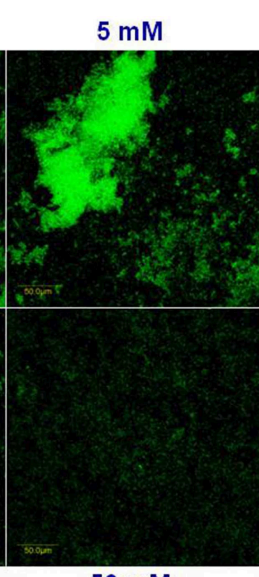

$50 \mathrm{mM}$
$10 \mathrm{mM}$

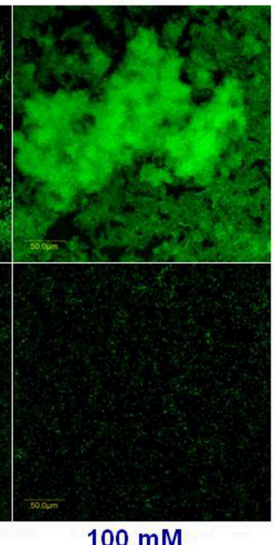

$100 \mathrm{mM}$
FIGURE 3 | $\mathbf{M g}^{2+}$ ions block the biofilm bundles formation of $\boldsymbol{B}$. subtilis. CLSM images of fluorescently tagged $B$. subtilis cells (YC161 with

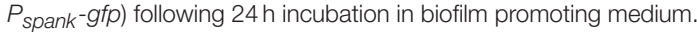

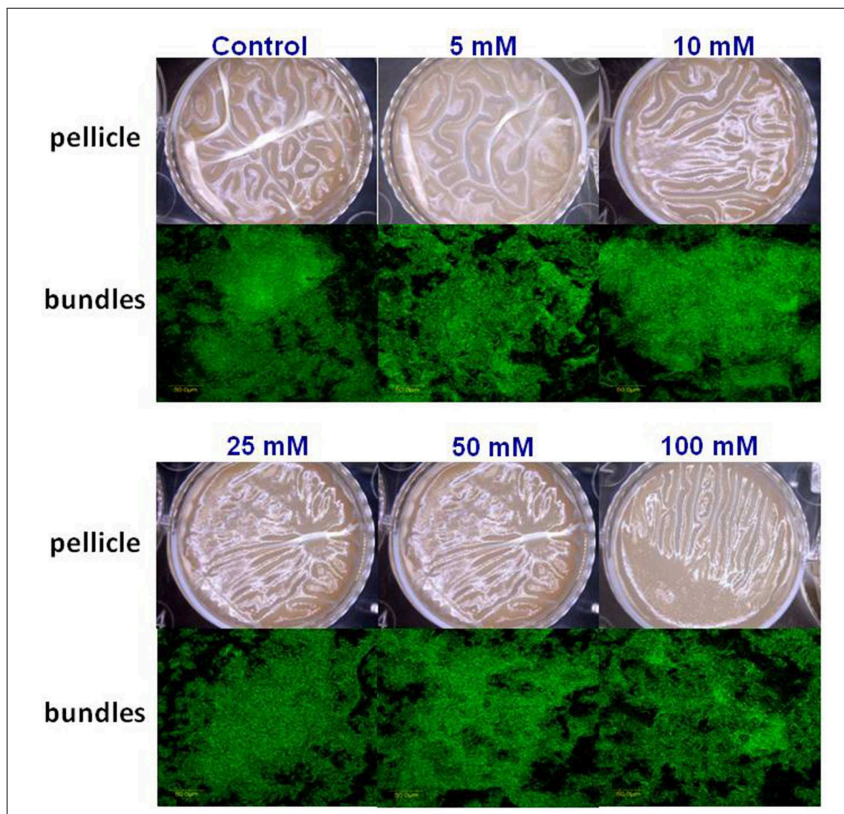

FIGURE 4 | The effect of $\mathrm{Na}^{+}$ions on biofilm formation by $B$. subtilis. The effect of addition of different concentrations of $\mathrm{NaCl}$ to LBGM medium on pellicle formation by $B$. subtilis NCIB3610.

It was proposed previously that high $\mathrm{Mg}^{2+}$ concentration might contribute to an increase in exopolysaccharide (EPS) production and biofilm stabilization (Costerton et al., 1995). However, it was also found that biofilm formation decreased with increasing concentration of $\mathrm{Mg}^{2+}$ in E. cloacae (Zhou et al., 2014). In our study, we showed that the expression of the two major operons responsible for biofilm matrix production were reduced notably in response to $\mathrm{Mg}^{2+}$ ions, suggesting about an inhibitory effect on expression of the matrix genes in B. subtilis. We demonstrated that $\mathrm{Mg}^{2+}$ ions are capable to

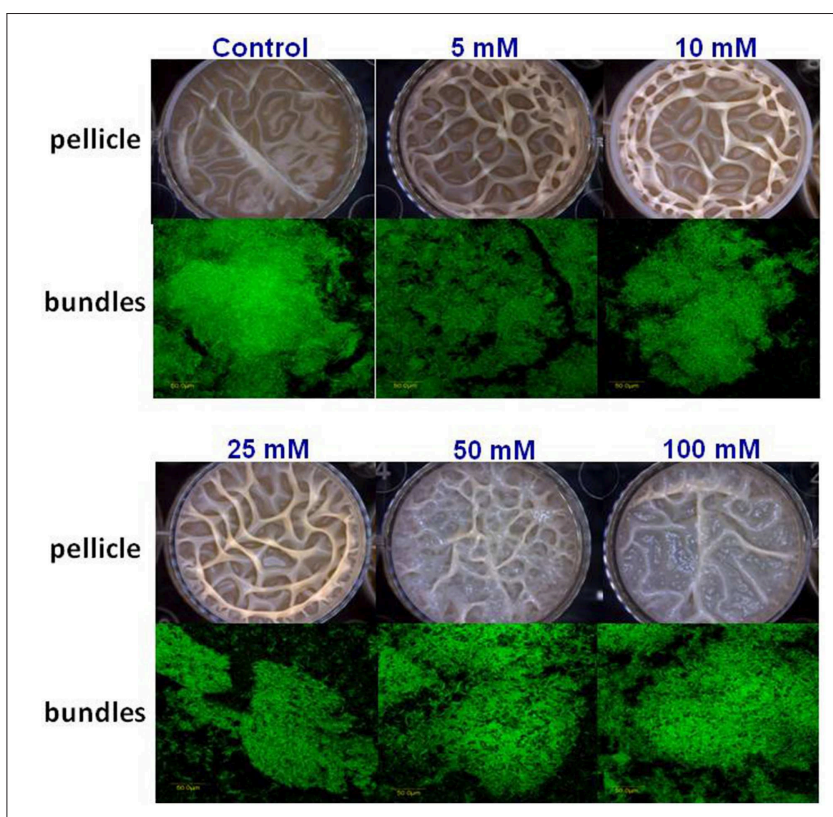

FIGURE 5 | The effect of $\mathrm{Ca}^{2+}$ ions on biofilm formation by $\mathrm{B}$. subtilis. The effect of addition of different concentrations of $\mathrm{CaCl}_{2}$ to $\mathrm{LBGM}$ medium on pellicle formation by $B$. subtilis NCIB3610.

profoundly inhibit biofilm formation of B. subtilis at $25 \mathrm{mM}$ concentration and higher. Since the matrix gene expression is tightly controlled by Spo0A P dependent pathway (Shemesh and Chai, 2013), it is conceivable that $\mathrm{Mg}^{2+}$ ions could affect the signal transduction for biofilm formation through this pathway. Although, it is also possible that matrix gene expression is alternatively turned on by a Spo $0 \mathrm{~A} \sim \mathrm{P}$ independent pathway such as YwcC-SlrA pathway (Chai et al., 2009). It will be interesting to further investigate in future studies how the inhibitory effect of $\mathrm{Mg}^{2+}$ ions affect a certain signaling pathway involved in biofilm formation.

In our study we decided to determine whether other divalent metal ions such as $\mathrm{Ca}^{2+}\left(\mathrm{CaCl}_{2}\right)$ or monovalent metal ions such as $\mathrm{Na}^{+}(\mathrm{NaCl})$ can inhibit biofilm formation. Our results showed that $\mathrm{Ca}^{2+}$ and $\mathrm{Na}^{+}$ions did not significantly decrease biofilm formation by $B$. subtilis. It is known that the $\mathrm{Ca}^{2+}$ ions have beneficial effect of on the mechanical stability of various biofilms (Rose, 2000). Moreover, it is also established that $\mathrm{Ca}^{2+}$ ions is important for bacterial biofilm formation (Geesey et al., 2000). Calcium is thought to promote thicker bacterial biofilms, primarily through ionic bridging of the extracellular matrix material (Rose and Turner, 1998; Körstgens et al., 2001). Previous studies have shown that the addition of $\mathrm{Ca}^{2+}$ caused a significant increase in $S$. paucimobilis biofilm formation at different concentration levels (Guvensen et al., 2012). Another study has shown that Pseudoalteromonas spp. produces larger amounts of biofilm-associated polysaccharide with increased $\mathrm{Ca}^{2+}$ (Patrauchan et al., 2005). Additional study showed that the amount of extracellular polysaccharide material of an alginateproducing of Pseudomonas aeruginosa is induced as much as eight-fold in response to $\mathrm{Ca}^{2+}$ ions (Sarkisova et al., 2005). It 
was also recently shown that $\mathrm{Na}^{+}$ions could also affect autoaggregation and biofilm formation in some foodborne pathogens (Xu et al., 2010).

In overall, results of the present study show the inhibitory effect of $\mathrm{Mg}^{2+}$ ions on B. subtilis biofilm formation as well as reduction in expression of main genes involved in biofilm formation. Findings of this study can open opportunities for development of novel strategies to control biofilm formation in various settings by using small natural molecules. Hence, different magnesium salts can be used to prevent or inhibit bacterial colonization and biofilm formation of Bacillus species in industrial and clinical settings.

\section{Acknowledgments}

Contribution from the Agricultural Research Organization, the Volcani Center, Beit Dagan, Israel, No. 720/15-E Series is

\section{References}

Branda, S. S., Chu, F., Kearns, D. B., Losick, R., and Kolter, R. (2006). A major protein component of the Bacillus subtilis biofilm matrix. Mol. Microbiol. 59, 1229-1238. doi: 10.1111/j.1365-2958.2005.05020.x

Branda, S. S., González-Pastor, J. E., Ben-Yehuda, S., Losick, R., and Kolter, R. (2001). Fruiting body formation by Bacillus subtilis. Proc. Natl. Acad. Sci. U.S.A. 98, 11621-11626. doi: 10.1073/pnas.191384198

Chai, Y., Chu, F., Kolter, R., and Losick, R. (2008). Bistability and biofilm formation in Bacillus subtilis. Mol. Microbiol. 67, 254-263. doi: 10.1111/j.13652958.2007.06040.X

Chai, Y., Kolter, R., and Losick, R. (2009). Paralogous antirepressors acting on the master regulator for biofilm formation in Bacillus subtilis. Mol. Microbiol. 74, 876-887. doi: 10.1111/j.1365-2958.2009.06900.x

Chai, Y., Norman, T., Kolter, R., and Losick, R. (2011). Evidence that metabolism and chromosome copy number control mutually exclusive cell fates in Bacillus subtilis. EMBO J. 30, 1402-1413. doi: 10.1038/emboj.2011.36

Chu, F., Kearns, D. B., Branda, S. S., Kolter, R., and Losick, R. (2006). Targets of the master regulator of biofilm formation in Bacillus subtilis. Mol. Microbiol. 59, 1216-1228. doi: 10.1111/j.1365-2958.2005.05019.x

Costerton, J. W. (1999). Introduction to biofilm. Int. J. Antimicrob. Agents 11, 217-221. discussion: 237-239. doi: 10.1016/S0924-8579(99)00018-7

Costerton, J. W., Lewandowski, Z., Caldwell, D. E., and Korber, D. R., and LappinScott, H. M. (1995). Microbial biofilms. Annu. Rev. Microbiol. 49, 711-745. doi: 10.1146/annurev.mi.49.100195.003431

Dunne, W. M. Jr, and Burd, E. M. (1992). The effects of magnesium, calcium, EDTA, and $\mathrm{pH}$ on the in vitro adhesion of Staphylococcus epidermidis to plastic. Microbiol. Immunol. 36, 1019-1027. doi: 10.1111/j.1348-0421.1992.tb02106.x

Flemming, H. C., and Wingender, J. (2010). The biofilm matrix. Nat. Rev. Microbiol. 8, 623-633. doi: 10.1038/nrmicro2415

Fletcher, M. (1988). Attachment of Pseudomonas fluorescens to glass and influence of electrolytes on bacterium-substratum separation distance. J. Bacteriol. 170, 2027-2030.

Flint, S. H., Bremer, P. J., and Brooks, J. D. (1997). Biofilms in dairy manufacturing plant - description, current concerns and methods of control. Biofouling 11, 81-97. doi: 10.1080/08927019709378321

Geesey, G. G., Wigglesworth-Cooksey, B., and Cooksey, K. E. (2000). Influence of calcium and other cations on surface adhesion of bacteria and diatoms: A review. Biofouling 15, 195-205. doi: 10.1080/08927010009 386310

Guvensen, N. C., Demir, S., and Ozdemir, G. (2012). Effects of magnesium and calcium cations on biofilm formation by Sphingomonas Paucimobilis from an industrial environment. Fresenius Environ. Bull. 21, 3685-3692. doi: 10.1016/j. copbio.2013.05.185 acknowledged. We would like to thank Dr. Y. Chai from the Northeastern University for B. subtilis strains and helpful discussions. We thank Dr. Michel Gohar for the B. cereus strain. We also acknowledge members of the Shemesh and Steinberg laboratories for helpful discussions and some technical assistance, especially Danielle duanis-assaf and Ievgeniia Ostrov. We are also grateful to Eduard Belausov from ARO for excellent technical assistance with confocal microscopy. This work was partially supported by the COST ACTION FA1202 BacFoodNet. The authors of the paper declare no conflict of interest.

\section{Supplementary Material}

The Supplementary Material for this article can be found online at: http://journal.frontiersin.org/article/10.3389/fmicb. 2015.00907

Hall-Stoodley, L., Costerton, J. W., and Stoodley, P. (2004). Bacterial biofilms: from the natural environment to infectious diseases. Nat. Rev. Microbiol. 2, 95-108. doi: $10.1038 /$ nrmicro821

Kearns, D. B., Chu, F., Branda, S. S., Kolter, R., and Losick, R. (2005). A master regulator for biofilm formation by Bacillus subtilis. Mol. Microbiol. 55, 739-749. doi: 10.1111/j.1365-2958.2004.04440.x

Kolter, R., and Greenberg, E. P. (2006). Microbial sciences: the superficial life of microbes. Nature 441, 300-302. doi: 10.1038/441300a

Körstgens, V., Flemming, H. C., Wingender, J., and Borchard, W. (2001). Influence of calcium ions on the mechanical properties of a model biofilm of mucoid Pseudomonas aeruginosa. Water Sci. Technol. 43, 49-57.

Mah, T. F., and O’Toole, G. A. (2001). Mechanisms of biofilm resistance to antimicrobial agents. Trends Microbiol. 9, 34-39. doi: 10.1016/S0966842X(00)01913-2

Malik, A., and Kakii, K. (2003). Intergeneric coaggregations among Oligotropha carboxidovorans and Acinetobacter species present in activated sludge. FEMS Microbiol. Lett. 224, 23-28. doi: 10.1016/S0378-1097(03)00391-4

Marcus, H., Austria, A., and Baker, N. R. (1989). Adherence of Pseudomonas aeruginosa to tracheal epithelium. Infect. Immun. 57, 1050-1053.

Merino, S., Gavín, R., Altarriba, M., Izquierdo, L., Maguire, M. E., and Tomás, J. M. (2001). The MgtE $\mathrm{Mg}^{2+}$ transport protein is involved in Aeromonas hydrophila adherence. FEMS Microbiol. Lett. 198, 189-195. doi: 10.1111/j.15746968.2001.tb10641.x

Patrauchan, M. A., Sarkisova, S., Sauer, K., and Franklin, M. J. (2005). Calcium influences cellular and extracellular product formation during biofilmassociated growth of a marine Pseudoalteromonas sp. Microbiology 151(Pt 9), 2885-2897. doi: 10.1099/mic.0.28041-0

Romero, D., Aguilar, C., Losick, R., and Kolter, R. (2010). Amyloid fibers provide structural integrity to Bacillus subtilis biofilms. Proc. Natl. Acad. Sci. U.S.A. 107, 2230-2234. doi: 10.1073/pnas.0910560107

Rose, R. K. (2000). The role of calcium in oral streptococcal aggregation and the implications for biofilm formation and retention. Biochim. Biophys. Acta 1475, 76-82. doi: 10.1016/S0304-4165(00)00048-9

Rose, R. K., and Turner, S. J. (1998). Extracellular volume in streptococcal model biofilms: effects of $\mathrm{pH}$, calcium and fluoride. Biochim. Biophys. Acta 1379, 185-190. doi: 10.1016/S0304-4165(97)00098-6

Sarkisova, S., Patrauchan, M. A., Berglund, D., Nivens, D. E., and Franklin, M. J. (2005). Calcium-induced virulence factors associated with the extracellular matrix of mucoid Pseudomonas aeruginosa biofilms. J. Bacteriol. 187, 4327-4337. doi: 10.1128/JB.187.13.43274337.2005

Sharma, M., and Anand, S. K. (2002). Biofilms evaluation as an essential component of HACCP for food/dairy industry - a case. Food Control 13, 469-477. doi: 10.1016/S0956-7135(01)00068-8 
Shemesh, M., and Chai, Y. (2013). A combination of glycerol and manganese promotes biofilm formation in Bacillus subtilis via histidine kinase KinD signaling. J. Bacteriol. 195, 2747-2754. doi: 10.1128/JB.00028-13

Shemesh, M., Kolter, R., and Losick, R. (2010). The biocide chlorine dioxide stimulates biofilm formation in Bacillus subtilis by activation of the histidine kinase KinC. J. Bacteriol. 192, 6352-6356. doi: 10.1128/JB.01025-10

Shemesh, M., Tam, A., and Steinberg, D. (2007). Expression of biofilm-associated genes of Streptococcus mutans in response to glucose and sucrose. J Med Microbiol. 56(Pt 11), 1528-1535. doi: 10.1099/jmm.0.47146-0

Simoes, M., Simoes, L. C., and Vieira, M. J. (2010). A review of current and emerging control strategies. LWT Food Sci. Technol. 43, 573-583. doi: 10.1016/j.lwt.2009.12.008

Simoni, S. F., Bosma, T. N. P., Harms, H., and Zehnder, A. J. B. (2000). Bivalent cations increase both the subpopulation of adhering bacteria and their adhesion efficiency in sand columns. Environ. Sci. Technol. 34, 1011-1017. doi: 10.1021/ es $990476 \mathrm{~m}$

Somerton, B., Flint, S., Palmer, J., Brooks, J., and Lindsay, D. (2013). Preconditioning with cations increases the attachment of Anoxybacillus flavithermus and Geobacillus species to stainless steel. Appl. Environ. Microbiol. 79, 4186-4190. doi: 10.1128/AEM.00462-13

Song, B., and Leff, L. G. (2006). Influence of magnesium ions on biofilm formation by Pseudomonas fluorescens. Microbiol. Res. 161, 355-361. doi: 10.1016/j.micres.2006.01.004

Stewart, P. S., and Costerton, J. W. (2001). Antibiotic resistance of bacteria in biofilms. Lancet 358, 135-138. doi: 10.1016/S0140-6736(01)05321-1
Tamura, G. S., Kuypers, J. M., Smith, S., Raff, H., and Rubens, C. E. (1994). Adherence of group B streptococci to cultured epithelial cells: roles of environmental factors and bacterial surface components. Infect. Immun. 62, 2450-2458.

Wirtanen, G., Husmark, U., and Mattila-Sandholm, T. (1996). Microbial evaluation of the biotransfer potential from surfaces with Bacillus biofilms after rinsing and cleaning procedures in closed food-processing systems. J. Food Prot. 59, 727-733.

$\mathrm{Xu}$, H., Zou, Y., Lee, H. Y., and Ahn, J. (2010). Effect of $\mathrm{NaCl}$ on the biofilm formation by foodborne pathogens. J. Food Sci. 75, M580-M585. doi: 10.1111/j.1750-3841.2010.01865.x

Zhou, G., Li, L. J., Shi, Q. S., Ouyang, Y. S., Chen, Y. B., and Hu, W. F. (2014). Efficacy of metal ions and isothiazolones in inhibiting Enterobacter cloacae BF17 biofilm formation. Can. J. Microbiol. 60, 5-14. doi: 10.1139/cjm-2013-0492

Conflict of Interest Statement: The authors declare that the research was conducted in the absence of any commercial or financial relationships that could be construed as a potential conflict of interest.

Copyright (c) 2015 Oknin, Steinberg and Shemesh. This is an open-access article distributed under the terms of the Creative Commons Attribution License (CC BY). The use, distribution or reproduction in other forums is permitted, provided the original author(s) or licensor are credited and that the original publication in this journal is cited, in accordance with accepted academic practice. No use, distribution or reproduction is permitted which does not comply with these terms. 